\title{
Optical Properties of Composites of Selected Shades
}

\author{
C.L. YEH, \# Y. MIYAGAWA, and J.M. POWERS\# \\ \#School of Dentistry. The University of Michigan, Ann Arbor, Michigan 48109, and Department of Dental Materials Science, Nippon Dental \\ University, Niigata, Japan
}

The optical properties of seven shades of a conventional composite and five shades of a microfilled composite were determined from reflection spectrophotometric data with Kubelka's equations. Scattering and absorption coefficients decreased and values of infinite optical thickness increased as wavelength increased from 405 to $700 \mathrm{~nm}$. Reflectivity curves were determined.

J Dent Res 61(6): 797-801, June 1982

\section{Introduction.}

Color is a physical property not of an object but rather of the light which is reflected from the object. The color of an object depends on its capacity to modify the color of the incident light. ${ }^{1}$ The appearance of a dental composite layer underlaid by some background material has been shown to be determined by (1) the absorption and internal scattering characteristics of the composite ${ }^{2,3}$ (2) the thickness of the composite, ${ }^{4}$ and (3) the light-reflecting properties of the background material. ${ }^{2,3}$

The optical behavior of light-scattering materials has been treated theoretically by Kubelka and $\mathrm{Munk}^{5}$ by the development of a relation for monochromatic light between the reflection of an infinitely thick layer of a material and its absorption and scattering coefficients. Several authors have applied the Kubelka-Munk theory to obtain optical constants of esthetic dental filling materials; ${ }^{6-8}$ however, the Kubelka-Munk formulae do not lend themselves to algebraic solution. In 1948 , $\mathrm{Kubelka}^{9}$ developed a theory and derived equations for optical properties that could be solved algebraically by hyperbolic functions. These equations have been used to describe the optical properties of universal shades of dental composites in white light. ${ }^{2}$

The purpose of this study was to determine the scattering coefficient, absorption coefficient, infinite optical thickness, and light reflectivity of shaded dental composites as a function of wavelength by Kubelka's equation.

\section{Materials and methods.}

One conventional brand ${ }^{*}(\mathrm{C})$ and one microfilled brand $\dagger$ (S) of paste-paste composite were used. Codes, shades, and batch numbers of the materials are listed in the Table.

Three sample disks $(36 \mathrm{~mm}$ in diameter and about $1.2 \mathrm{~mm}$ in thickness) were prepared following manufacturer's recommendations for each product by polymeriza-

Received for publication July 27,1981

Accepted for publication November 24, 1981

Dr. Yeh's current address is Department of Dentistry, National Defense Medical Center, Taipei, Taiwan.

Based on a thesis submitted in partial fulfillment of the requirements for the Master's Degree in the Horace H. Rackham School of Graduate Studies at The University of Michigan, 1981

This investigation was presented at the Annual Meeting of the International Association for Dental Research in New Orleans, LA, March, 1982.

Address reprint requests to Dr. Powers.

*Concise, 3M Company, St. Paul, MN 55101

†Silar, 3M Company, St. Paul, MN 55101
TABLE

CODES, PRODUCTS, BATCH NUMBERS, AND THICKNESSES OF SPECIMENS OF COMPOSITES TESTED

\begin{tabular}{|c|c|c|c|c|}
\hline Code & Product*** & Batch & Number & Thickness, mm \\
\hline $\mathrm{CU}$ & Concise Universal & $\begin{array}{l}\text { Base } \\
\text { Catalyst }\end{array}$ & $\begin{array}{l}- \text { OY } 27 \\
- \text { OX } 19=\end{array}$ & $1.19(0.01)^{\pi} \pi$ \\
\hline CY & Concise Yellow & Base & - OP1 & $1.15(0.02)$ \\
\hline $\mathrm{CDY}$ & Concise Dark Yellow & Base & $-O P 1$ & $1.17(0.01)$ \\
\hline CL & Concise Light & Base & $-9 \mathrm{~L} 1$ & $1.22(0.04)$ \\
\hline $\mathrm{CG}$ & Concise Gray & Base & $-\mathrm{ON} 2$ & $1.17(0.04)$ \\
\hline $\mathrm{CO}$ & Concise Opaque & Base & $-9335 \mathrm{~K} 1$ & $1.18(0.04)$ \\
\hline CT & Concise Translucent & Base & $-9039 Y_{1}$ & $1.19(0.04)$ \\
\hline $\mathrm{SU}$ & Silar Universal & $\begin{array}{l}\text { Base } \\
\text { Catalyst }\end{array}$ & $\begin{array}{l}-\mathrm{OP} 3 \\
-\mathrm{OM} 2 \ddagger \ddagger\end{array}$ & $1.10(0.04)$ \\
\hline SY & Silar Yellow & Base & - OE4 & $1.09(0.02)$ \\
\hline SDY & Silar Dark Yellow & Base & - OG4 & $1.14(0.04)$ \\
\hline SL & Silar Light & Base & -- OG3 & $1.14(0.03)$ \\
\hline SG & Silar Gray & Base & - OL2 & $1.14(0.04)$ \\
\hline
\end{tabular}

***Manufactured by 3M Company, St. Paul, MN 55101

$=$ Cataly st OX19 was used for all shades of C.

$\$ \neq$ Cataly st OM2 was used for all shades of S.

I Mean value of three samples with standard deviation in parentheses.

tion of the resin in a metal die. Two min after the mix was initiated, the samples were placed in an environment of $37 \pm 1^{\circ} \mathrm{C}$ and $95 \pm 5 \%$ relative humidity for $15 \mathrm{~min}$. Then the specimens were stored for $24 \mathrm{~h}$ in distilled water at $37 \pm 1^{\circ} \mathrm{C}$ before finishing. Surface finishes for both sides of samples were made with a metallurgical grinder and waterlubricated 600 grit abrasive papers. $\dagger \dagger$ The samples were stored in an environment of $23 \pm 2^{\circ} \mathrm{C}$ and $50 \pm 10 \%$ relative humidity for four $\mathrm{d}$ before testing. The actual thickness of samples was measured to the nearest $0.01 \mathrm{~mm}$ (see Table) for use in subsequent calculations.

A double-beam, ultraviolet-visible spectrophotometer $§ \S$ with an integrating sphere $\$$ was used to obtain reflectance data at wavelengths $(\lambda)$ at every $5 \mathrm{~nm}$ between 405 and 700 $\mathrm{nm}$ for combined specular and diffuse reflectance. The band-width of the monochromator was $2.0 \mathrm{~nm}$. A transmission blank $\$$ was used for calibration of zero reflectance. A white porcelain standard ${ }^{\infty}$ for which values of absolute reflectance were known at every $5 \mathrm{~nm}$ was evaluated in a sample port $(25 \mathrm{~mm}$ in diameter) with a barium sulfate standard in a reference port to obtain calibration coefficients at every $5 \mathrm{~nm}$.

Specimens for each product were evaluated in the sample port with the barium sulfate standard in the

\footnotetext{
† Gp-304, SIC Strips, Grit 600, Mager Scientific, Inc., Dexter, MI 48130

§ § ACT A C III UV-visible Spectrophotometer, Beckman Instruments, Inc., Irvine, CA 92664

\$ASPH-U Integrating Sphere, Beckman Instruments, Inc,, Irvine, CA 92664

$\S$ Part No. 587738, Beckman Instruments, Inc., Irvine, CA 92664

${ }^{\infty}$ Standard No. D33C-2051, Hunter Associates Laboratory, Inc., Fairfax, VA 22030

I Part No. 104384, Beckman Instruments, Inc., Irvine, CA
} 92664 
reference port under two conditions: (a) backed by a black standard, ${ }^{* *}$ and (b) backed by a white standard. 1 Reflectance values of the black standard and white standard were also obtained. The data were multiplied by the corresponding calibration coefficients to obtain absolute reflectance values.

The optical constants - including light reflectivity (RI), scattering coefficient (S), and absorption coefficient $(\mathrm{K})$ of the materials were calculated algebraically from the reflectance data of the samples as a function of wavelength at every $5 \mathrm{~nm}$ using Kubelka's equations ${ }^{9}$ as described below:

Secondary optical constants (a and b) ${ }^{9}$ were calculated by Equations (1)// and (2):

$$
\begin{aligned}
& a=\left[R(B)-R(W)-R_{B}+R_{W}-R(B) R(W)\right. \\
& R_{B}+R(B) R(W) R_{W}+R(B) R_{B} R_{W}-R(W) \\
& \left.R_{B} R_{W}\right] / 2\left[R(B) R_{W}-R(W) R_{B}\right]
\end{aligned}
$$

and

$$
b=\left(a^{2}-1\right)^{1 / 2}
$$

where $R_{B}$ is the reflectance of a dark backing (the black standard), $R_{W}$ is reflectance of a light backing (the white standard), $R(B)$ is the light reflectance of a sample with the dark backing, and $R(W)$ is the light reflectance of the sample with the light backing.

The light reflectivity ${ }^{9}$ (RI, the light reflectance of a material of infinite thickness) is defined by Equation (3):

$$
\mathbf{R I}=\mathrm{a}-\mathrm{b}
$$

The scattering coefficient $(\mathbf{S})^{9}$ for a unit thickness of a material is defined by Equation (4)

$$
\begin{gathered}
S=(1 / b X) \operatorname{Ar} \operatorname{ctgh}[1-a(R+R g)+R R g \\
/ b(R-R g)], m^{-1}
\end{gathered}
$$

where $X$ is the actual thickness of the sample, Ar ctgh is an inverse hyperbolic cotangent, and $R$ is the light reflectance of the sample with the backing of reflectance, $\mathrm{Rg}$. (5)

The absorption coefficient $(\mathbf{K})^{9}$ is defined by Equation

$$
\mathbf{K}=\mathbf{S}(\mathrm{a}-1), \mathrm{mm}^{-1}
$$

In addition to the above optical constants, a thickness (XI) at which the reflectance of the material with an ideal black background would attain the $99.9 \%$ value of its light reflectivity $(\mathbf{R I})^{3}$ was calculated at every $5 \mathrm{~nm}$ from Equation (6):

$$
\mathbf{X I}=(1 / b \mathbf{S}) \operatorname{Ar} \operatorname{ctgh}[(1-0.999 \text { a RI }) / 0.999 \text { b RI (Eq. 6) }
$$

XI can be regarded as an infinite optical thickness for monochromatic light of the corresponding wavelength.

Mean values and standard deviations of $\mathbf{S}, \mathbf{K}, \mathbf{R I}$, and XI were determined. The effects of shade and wavelength on the optical properties were studied by analysis of variance. ${ }^{10}$ Comparisons of mean values among shades were made with a Tukey interval ${ }^{11}$ calculated at the $95 \%$ level of confidence.

I Part No. 104384, Beckman Instruments, Inc., Irvine, CA 92664

**Part No. 375287, Beckman Instruments, Inc., Irvine, CA 92664

"Equations 1 and 4 were derived by Miyagawa and Powers. 3

\section{Results.}

Mean values of scattering coefficient (S) vs. wavelength are shown in Fig. 1 for $\mathrm{C}$ and in Fig. 2 for $\mathrm{S}$. Mean values of absorption coefficient $(\mathbf{K})$ vs. wavelength are shown in Fig. 3 for $\mathrm{C}$ and in Fig. 4 for $\mathrm{S}$. The amounts of light absorbed and scattered by the materials decreased as the wavelength of the light increased between 405 and $700 \mathrm{~nm}$.

The scattering coefficients of $\mathrm{C}$ and $\mathrm{S}$ varied with shade. The Tukey interval for comparisons of means among shades of $\mathrm{C}$ or $\mathrm{S}$ was $0.09 \mathrm{~mm}^{-1}$. Among the shades of $\mathrm{C}$, values for $\mathrm{CO}$ were highest, followed by those for CL, then $\mathrm{CU}$ and $\mathrm{CY}$, and then CDY, CT, and CG. Among the shades of $S$, values for $S L$ were highest, followed by those for $S U$ and then SY, SDY, and SG. A comparison of like shades of $C$ and $S$ indicated that scattering coefficients of $S$ were higher than those of $C$ between 405 and $460 \mathrm{~nm}$, but lower than those between 465 and $700 \mathrm{~nm}$.

The absorption coefficients of $\mathrm{C}$ and $\mathrm{S}$ also varied with shade. The Tukey interval for comparisons of means among shades of $\mathrm{C}$ or $\mathrm{S}$ was $0.07 \mathrm{~mm}^{-1}$. Among the shades of $\mathrm{C}$, values of $\mathrm{CDY}$ and $\mathrm{CO}$ were highest, followed by those for $\mathrm{CG}$ and then by those for CL, CT, and CU. Values of $\mathbf{K}$ for CY were also high at $405 \mathrm{~nm}$ but decreased more rapidly than did values for CDY and CO. Among the shades of $\mathrm{S}$, values of $\mathbf{K}$ for SDY and SG were highest, followed by those for SU and SL. Values of K for SY were high at $405 \mathrm{~nm}$ but decreased rapidly to values similar to those for SU and SL. A comparison of $\mathrm{C}$ and $\mathrm{S}$ indicated that absorption coefficients of SDY and SG were higher and those of SU and SL were lower than those corresponding shades of $C$ between 405 and $700 \mathrm{~nm}$. Below $500 \mathrm{~nm}$, the curve of SY was higher than that of CY, whereas between 505 and $700 \mathrm{~nm}$, the curve of CY was higher.

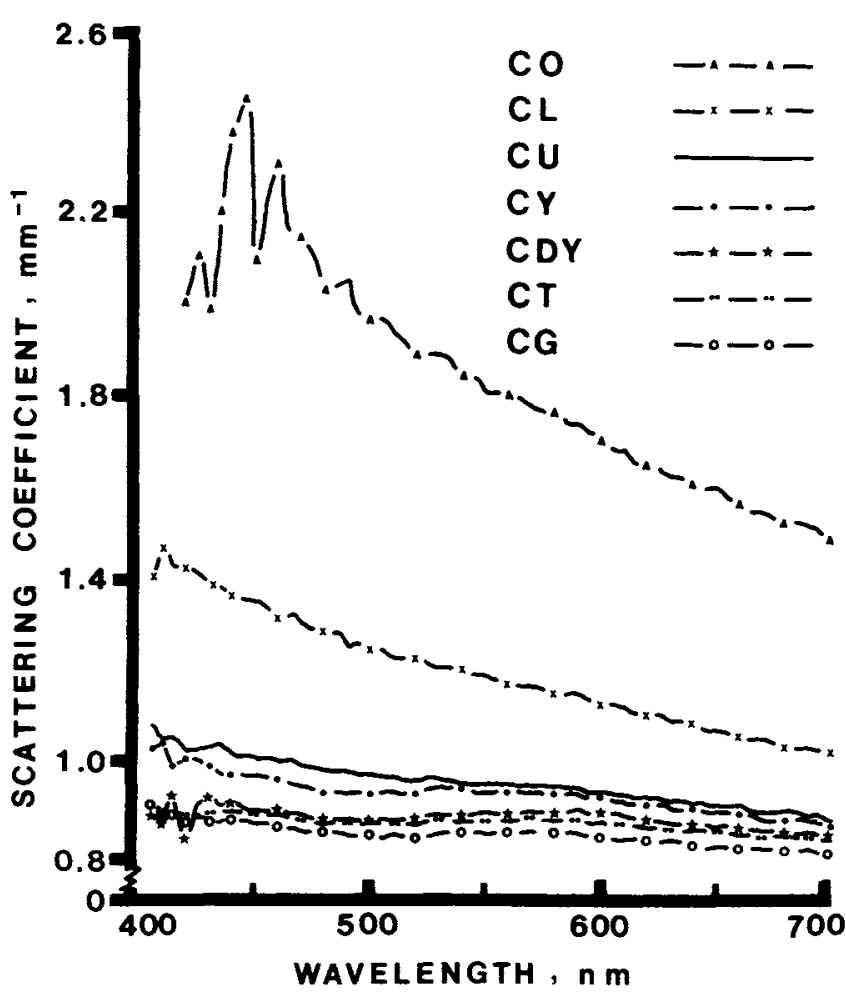

Fig. 1 - Scattering coefficient $v s$. wavelength for shades of $C$. 


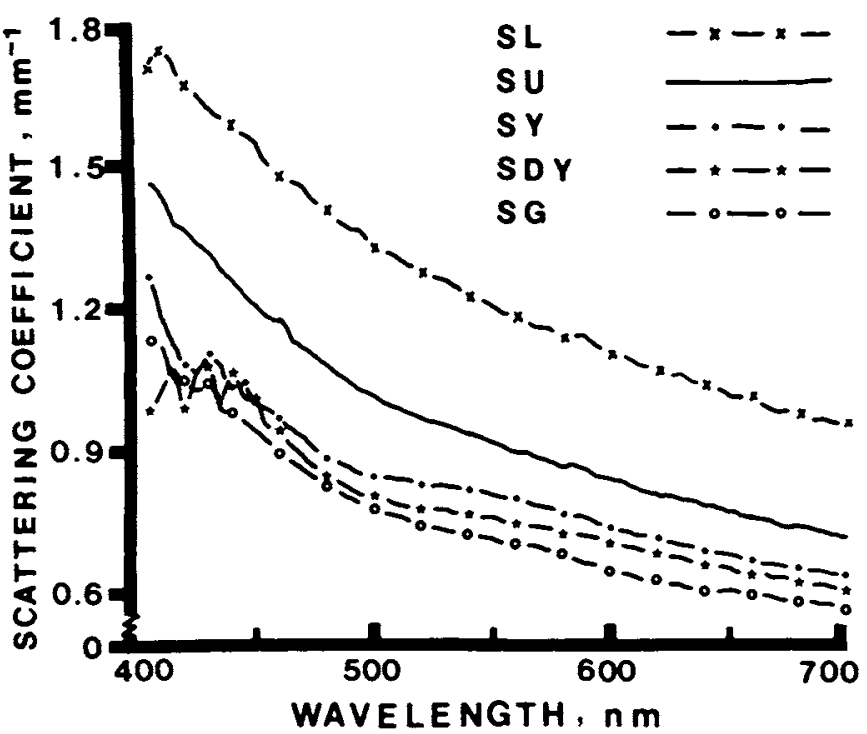

Fig. 2 - Scattering coefficient $v$ s. wavelength for shades of $S$.

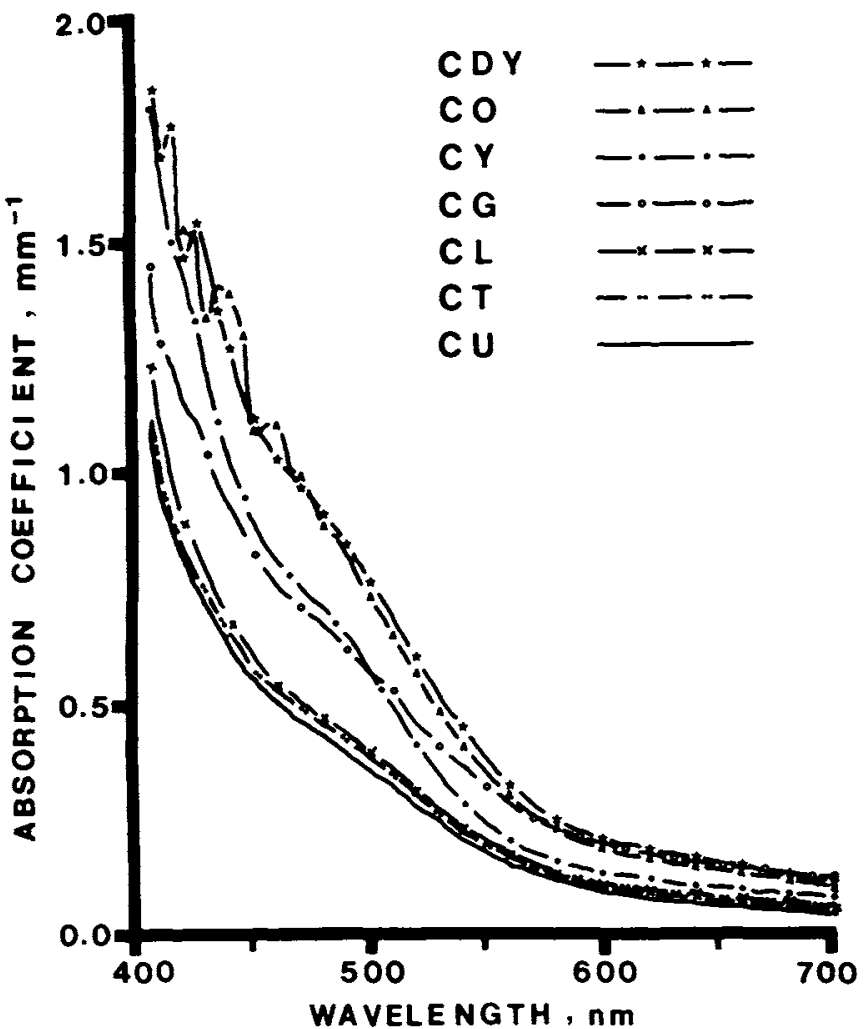

Fig. 3 - Absorption coefficient $v s$. wavelength for shades of C.

Mean values of infinite optical thicknesses (XI) vs. wavelength are plotted in Fig. 5 for C and Fig. 6 for S. Generally, the infinite optical thickness of shades of $C$ and $S$ increased as the wavelength increased between 405 and $700 \mathrm{~nm}$.

The values of infinite optical thickness of $C$ and $S$ varied with shade. The Tukey interval for comparisons of means among shades of $\mathrm{C}$ and $\mathrm{S}$ was $0.8 \mathrm{~mm}$. Among the shades of $\mathrm{C}$ between 550 and $700 \mathrm{~nm}$, values of XI of CU and CT were highest, followed by those of $\mathrm{CL}$ and $\mathrm{CY}$, then of $\mathrm{CG}$ and CDY, and then of CO. Among the shades of S between 550 and $700 \mathrm{~nm}$, values of XI of SU, SY, and SL were highest, followed by those of SDY and SG. Below $550 \mathrm{~nm}$, dif-

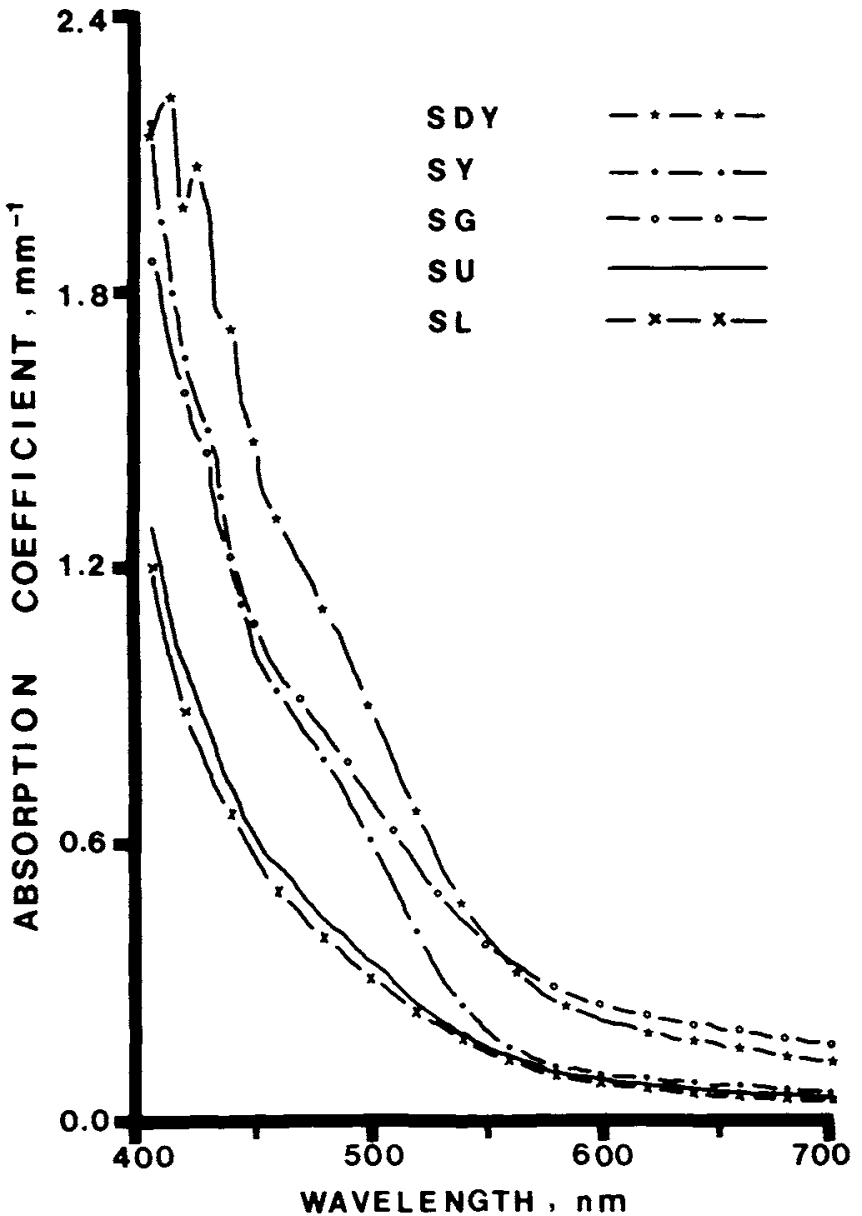

Fig. 4 - Absorption coefficient vs. wavelength for shades of $\mathrm{S}$.

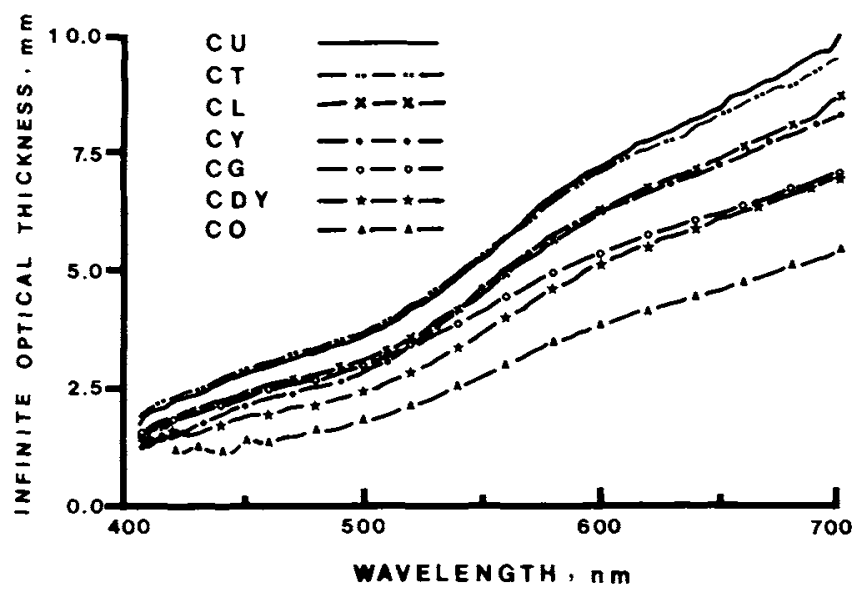

Fig. 5 - Infinite optical thickness vs. wavelength for shades of $C$.

ferences in XI among the shades were smaller. The variation of XI with wavelength for SY was different than for the other shades of $\mathrm{S}$. A comparison of like shades of $\mathrm{C}$ and $\mathrm{S}$ indicated that values of XI of $S$ were higher than those of $C$, except values of $S G$, which were lower than values of CG.

Light reflectivity curves are shown in Fig. 7 for $\mathrm{C}$ and Fig. 8 for $\mathrm{S}$. The Tukey interval for comparisons of means among shades of $\mathrm{C}$ or $\mathrm{S}$ was 0.01 . Light shades (CL and SL) had higher values of reflectivity than did other shades, 
whereas dark yellow (CDY and SDY) and gray (CG and SG) shades had lower values.

\section{Discussion.}

Previous studies ${ }^{2,6-8}$ of optical properties of esthetic restorative materials have used the tristimulus value $Y$ representing luminous reflectance in place of reflectance (R) in the Kubelka-Munk theory. The tristimulus value $\mathrm{Y}$, however, is sensitive to the light source, since the spectral energy distribution of the light source is used to calculate $Y^{5}$ Thus, optical properties calculated from Kubelka's equations with $Y$ are dependent on the light source. In the present study, optical properties were calculated with $R$ as a function of wavelength and are independent of light source. The constants $K$ and $S$ describe the optical characteristics of the composites at monochromatic wavelengths in the visible spectrum. As shown by Miyagawa and Powers, ${ }^{3}$ these constants can be used mathematically to predict the color of composites relative to any light source.

The scattering coefficient describes the rate of increase of reflectance with thickness of the composite. Scattering occurs where light encounters interfaces between resin and

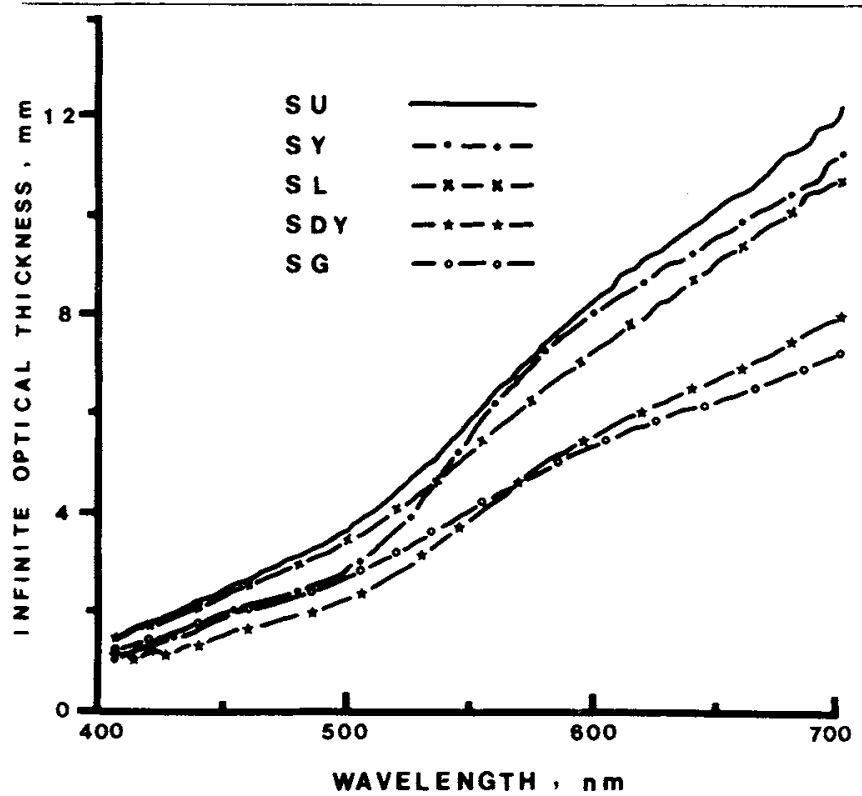

Fig. 6 - Infinite optical thickness vs. wavelength for shades of $S$.

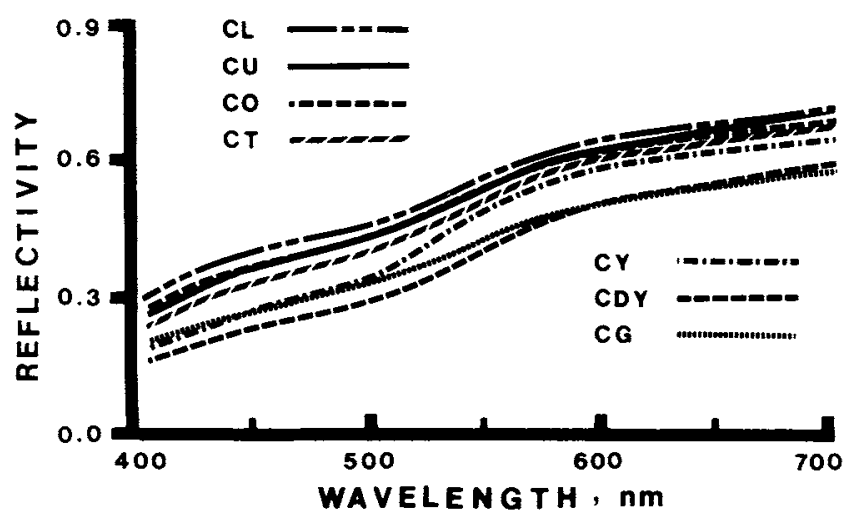

Fig. 7 - Light reflectivity $v$ s. wavelength for shades of $C$.

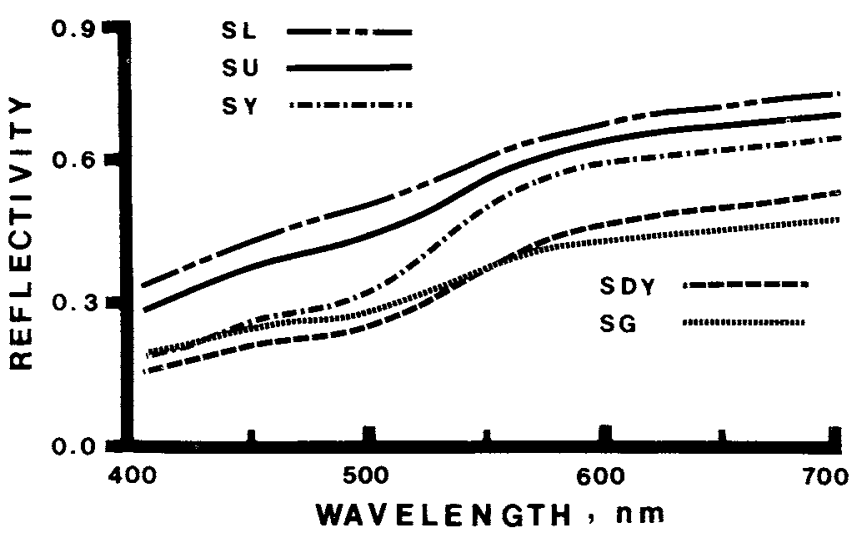

Fig. 8 - Light reflectivity vs. wavelength for shades of $S$.

filler or resin and pigment, for example, and increases with an increase in surface area of the particles. As particle size decreases to values less than the wavelength of the light, however, scattering is decreased. ${ }^{12}$ The conventional composite (C) has a filler content of $76.7 \%$ by weight quartz with an average particle size of $11 \mu \mathrm{m}$, whereas the microfilled composite (S) contains $49.7 \%$ by weight of colloidal silica with an average particle size of $0.04 \mu \mathrm{m} .{ }^{13}$ At lower wavelengths, $S$ causes more scattering than does $\mathrm{C}$, because $\mathrm{S}$ has a greater exposed surface area of its particles. At higher wavelengths, the smaller particles of $\mathrm{S}$ however, are less effective in scattering light, as shown in Fig. 2. The scattering of the shades $\mathrm{CO}$ and $\mathrm{CL}$ (Fig. 1) likewise shows a dependence on wavelength compared to that of other shades of $\mathrm{C}$.

The absorption coefficient describes the rate of decrease of transmittance with thickness of the composite. Color of the composite results from selective absorption of light at certain wavelengths by pigments in the composite or by the resin itself. The composites ( $\mathrm{C}$ and $\mathrm{S}$ ) demonstrate greater absorption at lower wavelengths, resulting in their yellow color relative to white light, as discussed elsewhere. $^{14}$ The more saturated shades (Y and DY) show higher absorption than do the less saturated shades ( $L$ and $U$ ). The saturations of $L$ and $U$ are further reduced by relatively high scattering. Likewise, the high absorption of the opaque shade $(\mathrm{CO})$ is accompanied by high scattering to reduce saturation.

The infinite optical thickness $(\mathbf{X I})$ represents the thickness at which a composite backed by a black background will attain $99.9 \%$ of its light reflectivity and become nearly opaque. The composites are more opaque to lower wavelengths than higher ones.

The reflectivity of the composites describes their reflectance when opaque and can be used to obtain the intrinsic color of the composites independent of background, as described elsewhere. ${ }^{14}$

\section{Conclusions.}

The optical properties of seven shades of a conventional composite (C) and five shades of a microfilled composite (S) were determined from reflection spectrophotometric data with Kubelka's equations. Scattering and absorption coefficients decreased, and values of infinite optical thickness increased as wavelength increased from 405 to $700 \mathrm{~nm}$ for both $\mathrm{C}$ and $\mathrm{S}$. Between 405 and $460 \mathrm{~nm}$, scattering coefficients of $\mathrm{S}$ were higher than values for like shades of $\mathrm{C}$ but lower between 465 and $700 \mathrm{~nm}$. Absorption 
coefficients and values of infinite optical thickness were higher for $\mathrm{S}$ than for $\mathrm{C}$ between 405 and $700 \mathrm{~nm}$.

\section{Acknowledgments.}

The cooperation of $3 \mathrm{M}$ Company for providing commercial materials is acknowledged.

Dr. Yeh acknowledges the financial support of the Government of the Republic of China and National Defense Medical Center, Taipei, Republic of China, for his graduate studies at The University of Michigan.

\section{REFERENCES}

1. American Society for Testing \& Materials: Spectrophotometry and Description of Color in CIE 1931 System. E 308-66 (1973). In: ASTM Recommended Practice, Part 46, Philadelphia, PA: ASTM, 1979, pp. 235-253.

2. MIYAGAWA, Y.; POWERS, J.M.; and O'BRIEN, W.J.: Optical Properties of Direct Restorative Materials, $J$ Dent Res 60: 890-894, 1981.

3. MIYAGAWA, Y. and POWERS, J.M.: Prediction of Color of an Esthetic Restorative Material, J Dent Res 60:582, 1981.

4. POWERS, J.M.; DENNISON, J.B.; and LEPEAK, P.: Param- eters that Affect the Color of Direct Restorative Resins, $J$ Dent Res 57:876-970, 1978 .

5. WYSZECKI, G. and STILES, W.S.: Color Science, New York, NY: John Wiley \& Sons, 1967, pp: 186-189.

6. JUDD, D.B.: Optical Specification of Light-Scattering Materials, RP 1026, J Res Natl Bur Stands 19:287-317, 1937.

7. STOREY, B.E. and JEFFREY, I.W.M.: The Clinical Implications of Some Optical Properties of Silicate Cement, J Dent $2: 77-84,1973$

8. CRISP, S.; ABEL, G.; and WILSON, A.D.: The Quantitative Measurement of the Opacity of Esthetic Dental Filling Materials, $J$ Dent Res 58:1585-1596, 1979.

9. KUBELKA, P.: New Contribution to the Optics of Intensely Light-scattering Materials. Part I, J Opt Soc Am 38:448-457, 1948.

10. DALBY, JOHN (Programmer): BMD8V - Analysis of Variance, Ann Arbor, MI: Statistical Research Laboratory, University of Michigan, 1968.

11. GUENTHER, W.C.: Analysis of Variance, Englewood Cliffs, NJ: Prentice-Hall, 1964, 199 pp.

12. HUNTER, R.S.: The Measurement of Appearance, New York, NY: Wiley-Interscience, 1975 , pp. 26-33.

13. CRAIG, R.G.: Chemistry, Composition, and Properties of Composite Resins, Den Clin North Am 25:219-239, 1981.

14. YEH, C.L.: The Color and Optical Properties of Shaded Composites. Master's Thesis, University of Michigan, Ann Arbor, MI, 1981, $104 \mathrm{pp}$. 